\title{
Review
}

Guideline/Fact Sheet

Diabetes Metab J 2020;44:3-10

https://doi.org/10.4093/dmj.2020.0004

pISSN 2233-6079 · eISSN 2233-6087

DIABET\&S \& METABOLISM JOURNAL

\section{Metformin Treatment for Patients with Diabetes and Chronic Kidney Disease: A Korean Diabetes Association and Korean Society of Nephrology Consensus Statement}

\author{
Kyu Yeon Hur ${ }^{1, *}$, Mee Kyoung Kim²,*, Seung Hyun Ko ${ }^{3}$, Miyeun Han ${ }^{4}$, Dong Won Lee ${ }^{5}$, Hyuk-Sang Kwon², Committee of \\ Clinical Practice Guidelines, Korean Diabetes Association and Committee of the Cooperative Studies, Korean Society of \\ Nephrology \\ ${ }^{1}$ Division of Endocrinology and Metabolism, Department of Medicine, Samsung Medical Center, Sungkyunkwan University School of Medicine, Seoul, \\ ${ }^{2}$ Division of Endocrinology and Metabolism, Department of Internal Medicine, Yeouido St. Mary's Hospital, College of Medicine, The Catholic University of \\ Korea, Seoul, \\ ${ }^{3}$ Division of Endocrinology and Metabolism, Department of Internal Medicine, St. Vincent's Hospital, College of Medicine, The Catholic University of Korea, \\ Suwon, \\ ${ }^{4}$ Division of Nephrology, Department of Internal Medicine, Pusan National University Hospital, Pusan National University School of Medicine, Busan, \\ ${ }^{5}$ Division of Nephrology, Department of Internal Medicine, Pusan National University School of Medicine, Yangsan, Korea
}

The safety of metformin use for patients with type 2 diabetes mellitus (T2DM) and advanced kidney disease is controversial, and more recent guidelines have suggested that metformin be used cautiously in this group until more definitive evidence concerning its safety is available. The Korean Diabetes Association and the Korean Society of Nephrology have agreed on consensus statements concerning metformin use for patients with T2DM and renal dysfunction, particularly when these patients undergo imaging studies using iodinated contrast media (ICM). Metformin can be used safely when the estimated glomerular filtration rate (eGFR) is $\geq 45 \mathrm{~mL} / \mathrm{min} / 1.73 \mathrm{~m}^{2}$. If the eGFR is between 30 and $44 \mathrm{~mL} / \mathrm{min} / 1.73 \mathrm{~m}^{2}$, metformin treatment should not be started. If metformin is already in use, a daily dose of $\leq 1,000 \mathrm{mg}$ is recommended. Metformin is contraindicated when the eGFR is $<30 \mathrm{~mL} /$ $\mathrm{min} / 1.73 \mathrm{~m}^{2}$. Renal function should be evaluated prior to any ICM-related procedures. During procedures involving intravenous administration of ICM, metformin should be discontinued starting the day of the procedures and up to 48 hours post-procedures if the eGFR is $<60 \mathrm{~mL} / \mathrm{min} / 1.73 \mathrm{~m}^{2}$.

Keywords: Contrast media; Diabetes mellitus; Metformin; Renal insufficiency

\section{INTRODUCTION}

Chronic kidney disease $(\mathrm{CKD})$ is a global public health prob- lem, and its prevalence is gradually increasing, mainly due to an increase in the number of patients with type 2 diabetes mellitus (T2DM) [1-4]. CKD develops in approximately $35 \%$ of
Corresponding authors: Dong Won Lee (1D https://orcid.org/0000-0003-0282-484X Division of Nephrology, Department of Internal Medicine, Pusan National University School of Medicine, 20 Geumo-ro, Mulgeum-eup, Yangsan 50612, Korea

E-mail: dongwonlee@pusan.ac.kr

Hyuk-Sang Kwon (1D https://orcid.org/0000-0003-4026-4572

Division of Endocrinology and Metabolism, Department of Internal Medicine, Yeouido

St. Mary's Hospital, College of Medicine, The Catholic University of Korea, 10 63-ro,

Yeongdeungpo-gu, Seoul 07345, Korea

E-mail: drkwon@catholic.ac.kr

This manuscript is simultaneously published in the Diabetes Metabolism Journal and in

Kidney Research and Clinical Practice by the Korean Diabetes Association and the

Korean Society of Nephrology.

${ }^{\star}$ Kyu Yeon Hur and Mee Kyoung Kim contributed equally to this study as first authors.

Received: Jan. 7, 2020; Accepted: Jan. 23, 2020
This is an Open Access article distributed under the terms of the Creative Commons Attribution Non-Commercial License (https://creativecommons.org/licenses/by-nc/4.0/) which permits unrestricted non-commercial use, distribution, and reproduction in any medium, provided the original work is properly cited.

Copyright $(2020$ Korean Diabetes Association

https://e-dmj.org 
patients with T2DM and is associated with increased mortality [1-4]. CKD stages are defined as follows [5]: CKD stage 1 (an estimated glomerular filtration rate $[\mathrm{eGFR}] \geq 90 \mathrm{~mL} / \mathrm{min} / 1.73 \mathrm{~m}^{2}$, normal or high), stage 2 (eGFR $60-89 \mathrm{~mL} / \mathrm{min} / 1.73 \mathrm{~m}^{2}$, mildly decreased), stage $3 a$ (eGFR $45-59 \mathrm{~mL} / \mathrm{min} / 1.73 \mathrm{~m}^{2}$, mildly to moderately decreased), stage $3 \mathrm{~b}$ (eGFR $30-44 \mathrm{~mL} / \mathrm{min} / 1.73 \mathrm{~m}^{2}$, moderately to severely decreased), stage 4 (eGFR $15-29 \mathrm{~mL} / \mathrm{min} /$ $1.73 \mathrm{~m}^{2}$, severely decreased), and stage 5 (eGFR $<15 \mathrm{~mL} / \mathrm{min} /$ $1.73 \mathrm{~m}^{2}$, kidney failure). According to a study conducted among elderly Canadian patients with diabetes mellitus (DM) [6], metformin continues to be prescribed to patients with advanced CKD stages 4 to 5 , although many guidelines and recommendations have suggested that metformin therapy be avoided because of its potential association with lactic acidosis and allcause mortality in patients with CKD stage 5 [7]. The safety of metformin in advanced kidney disease is controversial, and more recent guidelines have suggested cautious use in this patient group until more definitive evidence concerning its safety is made available [6,7]. For several decades, one of the most important limitations imposed by regulatory authorities on metformin use was related to renal function, for which a creatinine limit at $1.4 \mathrm{mg} / \mathrm{dL}$ for women and $1.5 \mathrm{mg} / \mathrm{dL}$ for men was established to contraindicate its use. In subsequent years, clinical studies and reviews were published that justified extending the use of metformin to patients with CKD stage 3 (i.e., an eGFR between 30 and $59 \mathrm{~mL} / \mathrm{min} / 1.73 \mathrm{~m}^{2}$ ) [8]. In 2016, the U.S. Food and Drug Administration (FDA) revised metformin's indication for use in patients with CKD stage 3 [9], whereas the indications for metformin use set by the Korean Ministry of Food and Drug Safety remain unchanged. In this report, we present the opinions of experts on the use of metformin according to renal function. The Korean Diabetes Association (KDA) and the Korean Society of Nephrology (KSN) have agreed on consensus statements for the use of metformin for patients with T2DM and renal dysfunction or patients undergoing imaging studies using iodinated contrast media (ICM).

\section{CURRENT STATUS OF METFORMIN USE IN PATIENTS WITH TYPE 2 DIABETES MELLITUS IN KOREA}

We investigated trends in the prescription of antidiabetic medications for patients with T2DM, focusing on renal function. Retrospective data involving patients with $\mathrm{T} 2 \mathrm{DM}$ aged $\geq 30$ years were analyzed using information from the National Health Information Database as collected by the National Health Insurance Service in Korea, from January 2009 to December 2015. This study was approved by the Institutional Review Board of Catholic University of Korea (No. SC19ZCSI0094). Anonymized and de-identified information was used
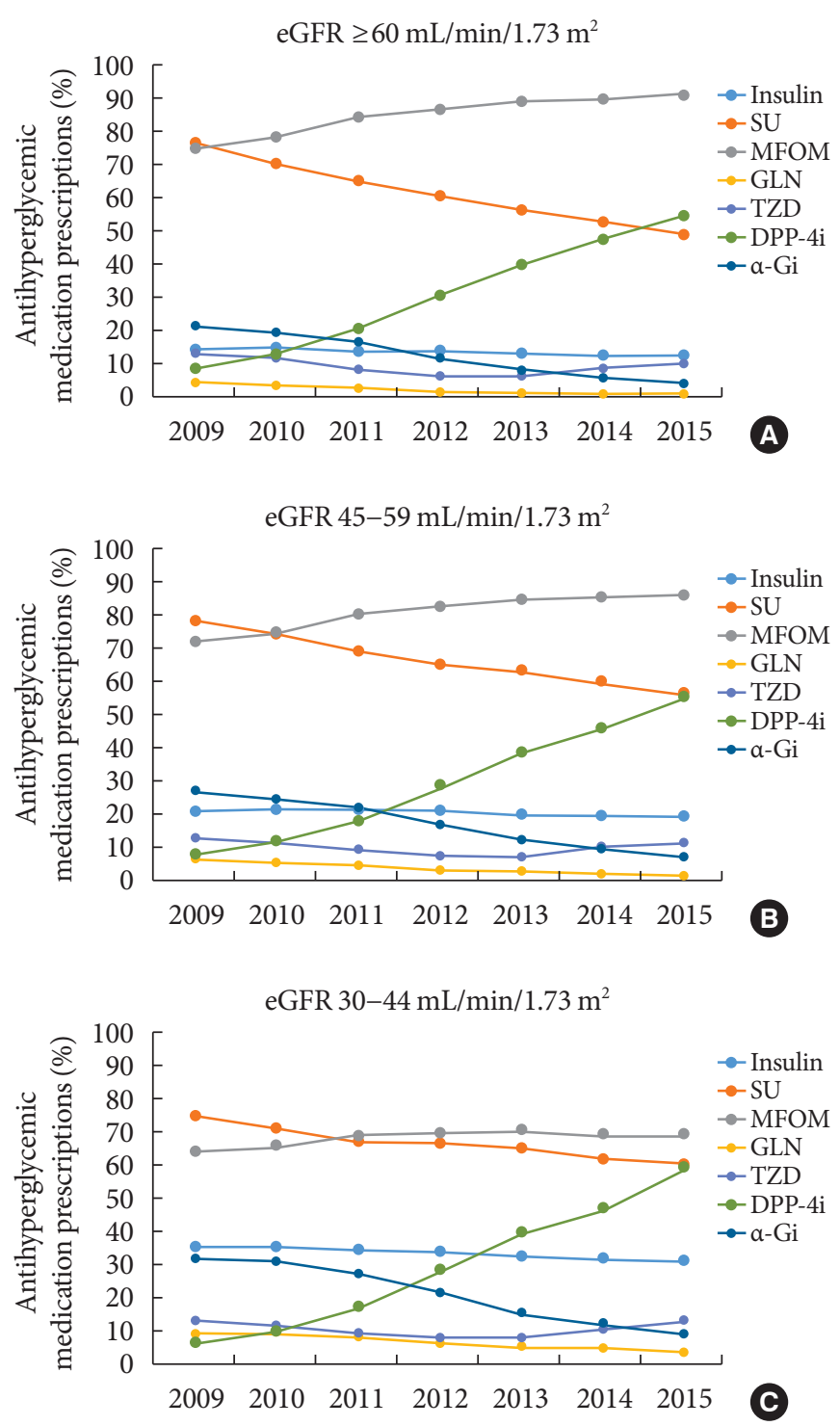

Fig. 1. Secular trends in antidiabetic medication prescriptions in adults with type 2 diabetes mellitus, according to kidney function: (A) in patients with an estimated glomerular filtration rate (eGFR) $\geq 60 \mathrm{~mL} / \mathrm{min} / 1.73 \mathrm{~m}^{2}$, (B) in patients with eGFR between 45 and $59 \mathrm{~mL} / \mathrm{min} / 1.73 \mathrm{~m}^{2}$, and (C) in patients with an eGFR between 30 and $44 \mathrm{~mL} / \mathrm{min} / 1.73 \mathrm{~m}^{2}$. SU, sulfonylurea; MFOM, metformin; GLN, glinide; TZD, thiazolidinedione; DPP-4i, dipeptidyl peptidase-4 inhibitor; $\alpha$-Gi, $\alpha$-glucosidase inhibitor. 
for analyses and, therefore, informed consent was waived. We identified patients with T2DM who had at least one service claim in each year during the study period. Among antidiabetic medications in 2009, sulfonylurea (SU) was the most commonly used agent (75.9\%), followed by metformin (74.7\%). However, in 2015, the use of metformin increased to $90.3 \%$ of all antidiabetic prescriptions (Fig. 1). The use of the dipeptidyl peptidase-4 (DPP-4) inhibitor began immediately after its release late in 2008 and dramatically increased to $54.3 \%$ in 2015. In contrast, the use of SU declined dramatically from $75.9 \%$ in 2009 to $48.4 \%$ in 2015. Among patients with an eGFR between 30 and $45 \mathrm{~mL} / \mathrm{min} / 1.73 \mathrm{~m}^{2}$, metformin was the most commonly used agent (68.6\%) in 2015, SU was the second-most commonly used agent (59.7\%), and DPP-4 inhibitor was the third-most commonly used agent (58.6\%). Therefore, we found that even among patients classified with CKD stage $3 \mathrm{~b}$, the use of metformin was relatively common in a real-world clinical setting.

Because of the potential risk of fatal lactic acidosis, metformin has long been under-prescribed, especially for patients with heart failure (HF) [10]. This situation has changed considerably following recent epidemiological studies that showed the risk of lactic acidosis associated with metformin use was not greater than that of other antidiabetic medications, and that metformin use in patients with DM and HF did not necessarily increase the risk of lactic acidosis $[11,12]$. We also found that the use of metformin was not associated with an increased incidence of HF in a case-control study of patients with T2DM who were first diagnosed with HF between 2013 and 2015 (Supplementary Table 1). We analyzed retrospective data on patients with T2DM from January 2013 to December 2015. We excluded those with a history of HF before the index year. Between 2013 and 2015, there were 97,178 incident HF cases in patients with T2DM. Potential case subjects were identified by International Classification of Diseases, 10th Revision (ICD-10) code I50 (HF). Control subjects were matched to each case subject according to age ( \pm 3 years) and sex. The index date for the control corresponded to the incidence date of the matched HF subject. The use of metformin was associated with a lower risk of $\mathrm{HF}$ (odds ratio [OR], 0.92; 95\% confidence interval [CI], 0.87 to 0.97 ), but the use of insulin was associated with an increased risk of HF (OR, 3.60; 95\% CI, 3.33 to 3.89). Similar results were obtained when the analysis was performed on a subset consisting of those who had received $\geq 2$ prescriptions of antidiabetic medication (Supplementary Table 1). A recent population-based retrospective cohort study in Taiwan reported a reduced risk of $\mathrm{HF}$ associated with metformin use in patients with T2DM [13].

\section{LACTIC ACIDOSIS ASSOCIATED WITH METFORMIN THERAPY}

Lactic acidosis, a well-known complication of biguanide therapy that usually occurs when lactic acid production exceeds lactic acid clearance, is generally defined as a blood $\mathrm{pH}<7.35$ and a blood lactate level $>45.0 \mathrm{mg} / \mathrm{dL}$ or $>5 \mathrm{mmol} / \mathrm{L}$. Lactic acidosis is a rare but potentially life-threatening complication, with a reported mortality risk approaching 50\% when the serum lactate level is $>23 \mathrm{mg} / \mathrm{dL}$ [14].

Phenformin induces conversion of glucose to lactate through the intestinal mucosa, enhances anaerobic metabolism, suppresses hepatic gluconeogenesis, and impairs renal excretion of lactate $[14,15]$. Since metformin is a type of biguanide with a chemical structure similar to that of phenformin, concerns have been raised regarding lactic acidosis. However, in contrast to phenformin, metformin does not inhibit glucose oxidation or interfere with lactate turnover or hydroxylation polymorphism and is not metabolized and excreted in the urine. Since the underlying mechanisms of these two drugs are different, the incidence of lactic acidosis in metformin therapy is theoretically considered to be lower than in phenformin therapy. Lactic acidosis is a rare event, with an estimated incidence of 4.3 cases per 100,000 person-years among metformin users [16]. Furthermore, evidence indicating that metformin increases the risk of lactic acidosis is lacking, and the frequency of lactic acidosis due to metformin is lower than expected. Most cases of lactic acidosis among metformin users were reported to have occurred when metformin was used inappropriately, such as in patients with severely decreased renal function $[17,18]$.

The term metformin-associated lactic acidosis (MALA) has been used to describe almost all cases of lactic acidosis observed in a metformin-treated patient. However, use of the word 'associated' is ambiguous. It is difficult to distinguish between lactic acidosis due to metformin accumulation (i.e., acute kidney injury [AKI] and voluntary intoxication) and systemic conditions (sepsis, cardiac failure, and bleeding) in patients taking metformin. One recent review article [19] emphasized that metformin therapy does not necessarily induce metformin accumulation, just as metformin accumulation 
does not necessarily induce hyperlactatemia, and hyperlactatemia does not necessarily induce lactic acidosis. Therefore, it is important to distinguish between metformin-unrelated lactic acidosis (MULA) and metformin-induced lactic acidosis (MILA). True MALA, which falls between MULA and MILA, is very rare [19].

\section{RECENT RECOMMENDATIONS ON THE USE OF METFORMIN IN CHRONIC KIDNEY DISEASE}

In 2016, the FDA [9] and the European Medicines Agency (EMA) [20] removed the contraindications concerning the use of metformin in patients with CKD stages $3 \mathrm{a}$ and $3 \mathrm{~b}$ (eGFR $30-44$ and $45-59 \mathrm{~mL} / \mathrm{min} / 1.73 \mathrm{~m}^{2}$, respectively). The FDA recommends metformin use in patients with T2DM and CKD as follows:

(1) Before starting metformin, obtain the patient's eGFR.

(2) Metformin is contraindicated in patients with an eGFR $<30 \mathrm{~mL} / \mathrm{min} / 1.73 \mathrm{~m}^{2}$.

(3) Starting metformin in patients with an eGFR between 30 and $45 \mathrm{~mL} / \mathrm{min} / 1.73 \mathrm{~m}^{2}$ is not recommended.

(4) Obtain an eGFR at least annually in all patients taking metformin.

(5) For patients at increased risk for the development of renal impairment, such as elderly patients, renal function should be assessed more frequently.

(6) For patients taking metformin whose eGFR later falls below $45 \mathrm{~mL} / \mathrm{min} / 1.73 \mathrm{~m}^{2}$, assess the benefits and risks of continuing treatment.

(7) Discontinue metformin if a patient's eGFR later falls below $30 \mathrm{~mL} / \mathrm{min} / 1.73 \mathrm{~m}^{2}$.

In addition, the EMA recommends dose reduction for patients with a moderate reduction in kidney function. Lalau et al. [21] recently published three complementary studies concerning the use of metformin for patients with T2DM and CKD stages $3 a$, $3 b$, or 4 , namely, a dose-finding study, a chronic metformin treatment study, and a pharmacokinetic study. On the basis of the dose-finding study results, they selected a chronic dosage regimen of $1,500 \mathrm{mg} /$ day for patients with T2DM and CKD stage 3a, 1,000 mg/day for patients with $\mathrm{T} 2 \mathrm{DM}$ and CKD stage $3 \mathrm{~b}$, and $500 \mathrm{mg} /$ day for patients with T2DM and CKD stage 4 (off-label use) [21].

The Korean Ministry of Food and Drug Safety continues to contraindicate the use of metformin for patients with T2DM and CKD stage $3 \mathrm{~b}$ (creatinine clearance $<45 \mathrm{~mL} / \mathrm{min}$ or an eGFR $<45 \mathrm{~mL} / \mathrm{min} / 1.73 \mathrm{~m}^{2}$ ). However, in 2019 , the KDA revised its recommendations as follows [22]: Metformin is contraindicated in patients with an eGFR $<30 \mathrm{~mL} / \mathrm{min} / 1.73 \mathrm{~m}^{2}$; Metformin can be used cautiously in patients with an eGFR between 30 and $45 \mathrm{~mL} / \mathrm{min} / 1.73 \mathrm{~m}^{2}$.

\section{IODINATED CONTRAST MEDIA- ASSOCIATED RENAL DAMAGE}

When ICM is used for patients with T2DM-related CKD, a patient's renal function should be considered based on CKD staging, the eGFR, and the risk of AKI [23,24]. The FDA has suggested the following risk factors that may warrant renal function assessment prior to contrast procedures: age $>60$ years, history of renal disease including dialysis, kidney transplantation, single kidney, renal cancer, renal surgery, history of hypertension requiring medical therapy, history of $\mathrm{DM}$, and metformin or metformin-containing drug combinations $[25,26]$.

Post-contrast AKI (PC-AKI) is a general term used to describe a sudden decline in renal function that occurs within 48 hours following intravascular administration of ICM; therefore, PC-AKI is a correlative diagnosis. However, contrast-induced nephropathy (CIN) is a more specific and causative diagnostic term in cases of sudden renal function decline due to the intravascular administration of ICM [27-32].

The exact pathophysiologic mechanism of CIN is not fully understood; however, some etiologic factors have been suggested, such as renal hemodynamic changes, direct tubular toxicity, or agent-specific chemotoxicity [33-36].

In Korea, contrast media was listed third among the most common causes of adverse drug reactions in 2018, following anticancer and nonsteroidal anti-inflammatory drugs. Moreover, 25 fatal cases have been reported in the past 5 years [37]. Therefore, the appropriate management for adverse reactions involving ICM is of growing importance; however, its current institutional management has not been assessed.

\section{IODINATED CONTRAST MEDIA- ASSOCIATED RENAL DAMAGE WHEN USING METFORMIN IN PATIENTS WITH TYPE 2 DIABETES MELLITUS-RELATED CHRONIC KIDNEY DISEASE}

Many concerns have been raised about MALA following ICM 
exposure, especially regarding patients who develop AKI while taking metformin. However, metformin does not confer an increased risk of CIN, and there have been no documented cases among properly selected patients [19,38,39]. The American College of Radiology (ACR) and the European Society of Urogenital Radiology (ESUR) have proposed more relaxed guidelines in recent years [40,41]. However, 57.1\% (32/56) of Korean hospitals and $53.3 \%$ (8/15) of hospitals outside Korea have been reported to discontinue metformin prior to contrast-enhanced computed tomography (CT) scans, regardless of a patient's renal function, and have failed to take into account upto-date guidelines [42]. The median cut-off eGFR for stopping metformin prior to contrast-enhanced CT scans has been reported to be $60 \mathrm{~mL} / \mathrm{min} / 1.73 \mathrm{~m}^{2}$ in Korean hospitals, which was significantly higher than that reported in hospitals outside Korea (30 or $44 \mathrm{~mL} / \mathrm{min} / 1.73 \mathrm{~m}^{2}$ ) [42]. The KSN conducted a simple survey on metformin use in 35 Korean university hospitals. The survey results indicated that metformin was usually stopped prior to contrast exposure, regardless of the patient's eGFR.

Metformin inhibits pyruvate carboxylase and induces excessive lactate production, inhibits the mitochondrial electron transport chain, and blocks the entry of pyruvate into the tricarboxylic acid cycle [43]. As mentioned earlier, MALA is very rare, and in almost all cases, lactic acidosis was reported to have occurred because of overlooked contraindications and several comorbid factors, such as cardiovascular, hepatic, or renal diseases [19,39].

\section{RECENT RECOMMENDATIONS REGARDING METFORMIN DISCONTINU-ATION PRIOR TO CONTRAST PROCEDURES}

In 2016, the FDA issued the following revised recommendation concerning the use of metformin for certain patients with reduced renal function:

(1) Discontinue metformin at the time of or prior to an iodinated contrast imaging procedure in patients with an eGFR between 30 and $60 \mathrm{~mL} / \mathrm{min} / 1.73 \mathrm{~m}^{2}$; in patients with a history of liver disease, alcoholism, or HF; or in patients who will be administered intra-arterial ICM.

(2) Re-evaluate eGFR 48 hours after the imaging procedure; restart metformin if renal function is stable [9].

In contrast, the ACR proposed more specific guidelines in 2018. The ACR guidelines recommend that patients taking metformin be classified into one of two categories, based on a patient's renal function, measured by the eGFR, as follows:

(1) Category I: In patients with no evidence of AKI and with an eGFR $\geq 30 \mathrm{~mL} / \mathrm{min} / 1.73 \mathrm{~m}^{2}$, there is no need to discontinue metformin either prior to or following intravenous administration of ICM, nor is there an obligatory need to reassess the patient's renal function following the test or procedure.

(2) Category II: In patients with AKI or severe CKD (stage 4 or 5 ; eGFR $<30 \mathrm{~mL} / \mathrm{min} / 1.73 \mathrm{~m}^{2}$ ) or patients who are undergoing intra-arterial contrast studies, metformin should be temporarily discontinued at the time of or prior to the procedure, withheld for 48 hours and reinstituted only after renal function has been re-evaluated and found to be normal [40].

The ESUR also focused on patients with an eGFR $<30 \mathrm{~mL} / \mathrm{min} /$ $1.73 \mathrm{~m}^{2}$, intra-arterial administration, and AKI. They distinguished between the risks of first or second pass renal exposure in intra-arterial administration. Patients with an eGFR $>30 \mathrm{~mL} / \mathrm{min} / 1.73 \mathrm{~m}^{2}$ and no evidence of AKI, receiving either intravenous ICM or intra-arterial ICM with second pass renal exposure, could continue taking metformin [41].

However, according to the Korean Ministry of Food and Drug Safety, even patients with an eGFR $>60 \mathrm{~mL} / \mathrm{min} / 1.73 \mathrm{~m}^{2}$ should discontinue metformin at the time of or prior to a contrast procedure. Moreover, patients with an eGFR between 45 and 60 $\mathrm{mL} / \mathrm{min} / 1.73 \mathrm{~m}^{2}$ should discontinue metformin 48 hours prior to and after the procedure, for a total of 96 hours [44].

In 2019, the KDA revised its recommendation that patients with an eGFR $<60 \mathrm{~mL} / \mathrm{min} / 1.73 \mathrm{~m}^{2}$ should discontinue metformin on the day of the procedure for up to 48 hours, and reinstituted metformin therapy if renal function has not declined following the procedures [22].

\section{KOREAN DIABETES ASSOCIATION AND KOREAN SOCIETY OF NEPHROLOGY JOINT CONSENSUS STATEMENTS ON THE USE OF METFORMIN IN DIABETES}

(1) Metformin can be used when the eGFR is $\geq 45 \mathrm{~mL} /$ $\min / 1.73 \mathrm{~m}^{2}$.

(2) If the eGFR is $30-44 \mathrm{~mL} / \mathrm{min} / 1.73 \mathrm{~m}^{2}$, do not start metformin treatment. If metformin is already in use, administer a daily dose of $\leq 1,000 \mathrm{mg}$.

(3) Metformin is contraindicated when the eGFR is $<30$ $\mathrm{mL} / \mathrm{min} / 1.73 \mathrm{~m}^{2}$. 
(4) Evaluate renal function before any procedures involving the use of ICM.

(5) Any decision to use ICM and whether to stop metformin should be based on renal function test results.

(6) During procedures involving intra-arterial administration of ICM, metformin should be discontinued starting the day of the procedures and up to 48 hours after the procedures.

(7) During procedures involving intravenous administration of ICM, metformin should be discontinued starting the day of the procedures and up to 48 hours after the procedures if eGFR is $<60 \mathrm{~mL} / \mathrm{min} / 1.73 \mathrm{~m}^{2}$.

(8) Re-evaluate renal function after procedures involving the use of ICM, and re-administer metformin if renal function has not declined after the procedures.

\section{SUPPLEMENTARY MATERIALS}

Supplementary materials related to this article can be found online at https://doi.org/10.4093/dmj.2020.0004.

\section{CONFLICTS OF INTEREST}

No potential conflict of interest relevant to this article was reported.

\section{ORCID}

Kyu Yeon Hur https://orcid.org/0000-0002-3065-7252

Mee Kyoung Kim https://orcid.org/0000-0003-3205-9114

Dong Won Lee https://orcid.org/0000-0003-0282-484X

Hyuk-Sang Kwon https://orcid.org/0000-0003-4026-4572

\section{ACKNOWLEDGMENTS}

This work was performed through the cooperation of the National Health Insurance Service (NHIS) and the Korean Diabetes Association. The results do not necessarily represent the opinion of the National Health Insurance Corporation.

\section{REFERENCES}

1. Kim KS, Park SW, Cho YW, Kim SK. Higher prevalence and progression rate of chronic kidney disease in elderly patients with type 2 diabetes mellitus. Diabetes Metab J 2018;42:224-32.

2. Bae JC. Trends of diabetes epidemic in Korea. Diabetes Metab J 2018;42:377-9.

3. Kim KJ, Kwon TY, Yu S, Seo JA, Kim NH, Choi KM, Baik SH, Choi DS, Kim SG, Park Y, Kim NH. Ten-year mortality trends for adults with and without diabetes mellitus in South Korea, 2003 to 2013. Diabetes Metab J 2018;42:394-401.

4. Kim BY, Won JC, Lee JH, Kim HS, Park JH, Ha KH, Won KC, Kim DJ, Park KS. Diabetes fact sheets in Korea, 2018: an appraisal of current status. Diabetes Metab J 2019;43:487-94.

5. Inker LA, Astor BC, Fox CH, Isakova T, Lash JP, Peralta CA, Kurella Tamura M, Feldman HI. KDOQI US commentary on the 2012 KDIGO clinical practice guideline for the evaluation and management of CKD. Am J Kidney Dis 2014;63:713-35.

6. Clemens KK, Liu K, Shariff S, Schernthaner G, Tangri N, Garg AX. Secular trends in antihyperglycaemic medication prescriptions in older adults with diabetes and chronic kidney disease: 2004-2013. Diabetes Obes Metab 2016;18:607-14.

7. Hung SC, Chang YK, Liu JS, Kuo KL, Chen YH, Hsu CC, Tarng DC. Metformin use and mortality in patients with advanced chronic kidney disease: national, retrospective, observational, cohort study. Lancet Diabetes Endocrinol 2015;3:60514.

8. American Diabetes Association. 9. Pharmacologic approaches to glycemic treatment: standards of medical care in diabetes-2019. Diabetes Care 2019;42(Suppl 1):S90-102.

9. U.S. Food and Drug Administration: FDA Drug Safety Communication: FDA revises warnings regarding use of the diabetes medicine metformin in certain patients with reduced kidney function. Available from: http://www.fda.gov/Drugs/ DrugSafety/ucm493244.htm (cited 2020 Jan 28).

10. Packer M. Is metformin beneficial for heart failure in patients with type 2 diabetes? Diabetes Res Clin Pract 2018;136:168-70.

11. Aharaz A, Pottegard A, Henriksen DP, Hallas J, Beck-Nielsen $\mathrm{H}$, Lassen AT. Risk of lactic acidosis in type 2 diabetes patients using metformin: a case control study. PLoS One 2018;13: e0196122.

12. Lee EY, Hwang S, Lee YH, Lee SH, Lee YM, Kang HP, Han E, Lee W, Lee BW, Kang ES, Cha BS, Lee HC. Association between metformin use and risk of lactic acidosis or elevated lactate concentration in type 2 diabetes. Yonsei Med J 2017;58: 312-8.

13. Tseng $\mathrm{CH}$. Metformin use is associated with a lower risk of hospitalization for heart failure in patients with type 2 diabetes mellitus: a retrospective cohort analysis. J Am Heart Assoc 
2019;8:e011640.

14. Chan NN, Brain HP, Feher MD. Metformin-associated lactic acidosis: a rare or very rare clinical entity? Diabet Med 1999; 16:273-81.

15. Oates NS, Shah RR, Idle JR, Smith RL. Influence of oxidation polymorphism on phenformin kinetics and dynamics. Clin Pharmacol Ther 1983;34:827-34.

16. Richy FF, Sabido-Espin M, Guedes S, Corvino FA, GottwaldHostalek U. Incidence of lactic acidosis in patients with type 2 diabetes with and without renal impairment treated with metformin: a retrospective cohort study. Diabetes Care 2014;37:22915.

17. Luft D, Schmulling RM, Eggstein M. Lactic acidosis in biguanide-treated diabetics: a review of 330 cases. Diabetologia 1978;14:75-87.

18. Lalau JD. Lactic acidosis induced by metformin: incidence, management and prevention. Drug Saf 2010;33:727-40.

19. Lalau JD, Kajbaf F, Protti A, Christensen MM, De Broe ME, Wiernsperger N. Metformin-associated lactic acidosis (MALA): moving towards a new paradigm. Diabetes Obes Metab 2017; 19:1502-12

20. European Medicines Agency: Note for guidance on the evaluation of the pharmacokinetics of medicinal products in patients with impaired renal function. Available from: http://www.ema. europa.eu/docs/en_GB/document_library/Scientific_guideline/2009/09/WC500003123.pdf (cited 2020 Jan 28).

21. Lalau JD, Kajbaf F, Bennis Y, Hurtel-Lemaire AS, Belpaire F, De Broe ME. Metformin treatment in patients with type 2 diabetes and chronic kidney disease stages $3 \mathrm{~A}, 3 \mathrm{~B}$, or 4 . Diabetes Care 2018;41:547-53.

22. Kim MK, Ko SH, Kim BY, Kang ES, Noh J, Kim SK, Park SO, Hur KY, Chon S, Moon MK, Kim NH, Kim SY, Rhee SY, Lee KW, Kim JH, Rhee EJ, Chun S, Yu SH, Kim DJ, Kwon HS, Park KS; Committee of Clinical Practice Guidelines, Korean Diabetes Association. 2019 Clinical practice guidelines for type 2 diabetes mellitus in Korea. Diabetes Metab J 2019;43:398-406.

23. Herts BR, Schneider E, Poggio ED, Obuchowski NA, Baker ME. Identifying outpatients with renal insufficiency before contrast-enhanced CT by using estimated glomerular filtration rates versus serum creatinine levels. Radiology 2008;248:10613.

24. Davenport MS, Khalatbari S, Cohan RH, Ellis JH. Contrast medium-induced nephrotoxicity risk assessment in adult inpatients: a comparison of serum creatinine level- and estimated glomerular filtration rate-based screening methods. Radiology
2013;269:92-100.

25. Choyke PL, Cady J, DePollar SL, Austin H. Determination of serum creatinine prior to iodinated contrast media: is it necessary in all patients? Tech Urol 1998;4:65-9.

26. Tippins RB, Torres WE, Baumgartner BR, Baumgarten DA. Are screening serum creatinine levels necessary prior to outpatient CT examinations? Radiology 2000;216:481-4.

27. Baumgarten DA, Ellis JH. Contrast-induced nephropathy: contrast material not required? AJR Am J Roentgenol 2008; 191:383-6.

28. Davenport MS, Cohan RH, Khalatbari S, Ellis JH. The challenges in assessing contrast-induced nephropathy: where are we now? AJR Am J Roentgenol 2014;202:784-9.

29. Ellis JH, Cohan RH. Reducing the risk of contrast-induced nephropathy: a perspective on the controversies. AJR Am J Roentgenol 2009;192:1544-9.

30. Katzberg RW, Newhouse JH. Intravenous contrast mediuminduced nephrotoxicity: is the medical risk really as great as we have come to believe? Radiology 2010;256:21-8.

31. McDonald JS, McDonald RJ, Carter RE, Katzberg RW, Kallmes DF, Williamson EE. Risk of intravenous contrast material-mediated acute kidney injury: a propensity score-matched study stratified by baseline-estimated glomerular filtration rate. Radiology 2014;271:65-73.

32. Newhouse JH, RoyChoudhury A. Quantitating contrast medium-induced nephropathy: controlling the controls. Radiology 2013;267:4-8

33. Heinrich MC, Kuhlmann MK, Grgic A, Heckmann M, Kramann B, Uder M. Cytotoxic effects of ionic high-osmolar, nonionic monomeric, and nonionic iso-osmolar dimeric iodinated contrast media on renal tubular cells in vitro. Radiology 2005; 235:843-9.

34. Sendeski M, Patzak A, Pallone TL, Cao C, Persson AE, Persson $\mathrm{PB}$. Iodixanol, constriction of medullary descending vasa recta, and risk for contrast medium-induced nephropathy. Radiology 2009;251:697-704.

35. Haight AE, Kaste SC, Goloubeva OG, Xiong XP, Bowman LC. Nephrotoxicity of iopamidol in pediatric, adolescent, and young adult patients who have undergone allogeneic bone marrow transplantation. Radiology 2003;226:399-404.

36. Senthilnathan S, Gauvreau K, Marshall AC, Lock JE, Bergersen L. Contrast administration in pediatric cardiac catheterization: dose and adverse events. Catheter Cardiovasc Interv 2009;73: 814-20.

37. Korean Institute of Drug Safety \& Risk Management: Drug 
safety information report trend (2018). Available from: open. drugsafe.or.kr/trend/trend/Read.jsp?ntt_id=2124 (updated 2019 Mar 4).

38. Shah AD, McHargue C, Yee J, Rushakoff RJ. Intravenous contrast in patients with diabetes on metformin: new common sense guidelines. Endocr Pract 2016;22:502-5.

39. Goergen SK, Rumbold G, Compton G, Harris C. Systematic review of current guidelines, and their evidence base, on risk of lactic acidosis after administration of contrast medium for patients receiving metformin. Radiology 2010;254:261-9.

40. ACR Committee on Drugs and Contrast Media: ACR manual on contrast media. Version 10.3. 2018. Available from: https:// www.acr.org/-/media/ACR/Files/Clinical-Resources/Contrast_ Media.pdf (updated 2017 May 31).

41. European Society of Urogenital Radiology: ESUR guidelines on contrast agents. Version 10.0. Available from: http://www.esur. org/fileadmin/content/2019/ESUR_Guidelines_10.0_Final_ Version.pdf (cited 2020 Jan 28).

42. Han S, Yoon SH, Lee W, Choi YH, Kang DY, Kang HR. Management of adverse reactions to iodinated contrast media for computed tomography in Korean referral hospitals: a survey investigation. Korean J Radiol 2019;20:148-57.

43. Corremans R, Vervaet BA, D'Haese PC, Neven E, Verhulst A. Metformin: a candidate drug for renal diseases. Int J Mol Sci 2018;20:E42.

44. Korea Ministry of Food and Drug Safety: Instructions on the change of permit for metformin hydrochloride (tablet) (uniform adjustment). Available from: https://nedrug.mfds.go.kr/ bbs/58/2683/ (updated $2018 \operatorname{Jan} 3$ ). 